\title{
Resíduos de agrotóxicos potencialmente contidos na dieta habitual de escolares
}

\author{
Ana Paula Gasques Meira ${ }^{1}$ e Marina Vieira da Silva ${ }^{2}$
}

O estudo estima a Ingestão Diária Máxima Teórica (IDMT) dos agrotóxicos potencialmente contidos na dieta habitual dos escolares $(n=341)$ matriculados no ensino público do município de Guariba (São Paulo) e compara os resultados com a Ingestão Diária Aceitável (IDA) estabelecida por órgãos reguladores. O cálculo da Ingestão Diária Máxima Teórica (IDMT) utiliza dados de consumo de alimentos dos escolares (Recordatórios de 24 horas), parâmetros de Limite Máximo de Resíduos (LMR) definidos pela Agência Nacional de Vigilância Sanitária (ANVISA) e Codex Alimentarius e a Ingestão Diária Aceitável (IDA) adotada por quatro órgãos (Agência Nacional de Vigilância Sanitária - ANVISA, Codex Alimentarius, Environmental Protection Agency - EPA e governo da Austrália). Os valores medianos de ingestão (estimada) de nove, do total de 272 agrotóxicos potencialmente presentes na dieta dos escolares, superaram a IDA estabelecida pela ANVISA. A ingestão máxima de 58 agrotóxicos excedeu os limites estabelecidos pela ANVISA, revelando a necessidade da redução imediata, conforme a lei que regulamenta o uso dos agrotóxicos no Brasil, dos níveis dessas substâncias em alimentos tradicionais da dieta da população brasileira, tendo em vista os riscos à saúde, notadamente das crianças.

Palavras-chave: Segurança Alimentar e Nutricional, avaliação de risco, resíduo de agrotóxico, exposição aos agrotóxicos, consumo alimentar.

\section{Pesticide residue potentially contained in the usual diet of schoolchildren}

The study estimates the theoretical maximum daily intake of pesticides potentially contained in the habitual diet of schoolchildren $(n=341)$ enrolled in public education in the city of Guariba (São Paulo) and compares the results with the Acceptable Daily Intake (ADI) by regulatory agencies. The theoretical maximum daily intake calculation uses schoolchildren's food consumption data (24-hour Reminders), Maximum Residue Limit (MRL) parameters defined by the National Health Surveillance Agency (ANVISA) and Codex Alimentarius, and the Acceptable daily intake (ADI) adopted by four agencies (National Health Surveillance Agency (ANVISA), Codex Alimentarius, Environmental Protection Agency (EPA) and government of Australia). The median values of (estimated) intake of nine out of 272 pesticides potentially present in the schoolchildren's diet exceeded the

${ }^{1}$ Mestre em Ciências - ESALQ - USP. Prefeitura Municipal de Iracemápolis. Endereço para correspondência: Rua Fortunata de Pareschi Demarchi no 130 - Jardim Alcides Modenez, Iracemápolis - SP, CEP 13495-000.E-mail: anapuava@gmail.com

2 Professora Doutora - ESALQ - USP.E-mail: marinavieiradasilva@usp.br 
ADI established by ANVISA. The maximum intake of 58 agrochemicals exceeded the limits established by ANVISA, revealing the need to immediately reduce, according to the law that regulates the use of pesticides in Brazil, the levels of these substances in traditional foods of the Brazilian population, considering the risks health, especially of children.

Keywords: Food and Nutritional Security, risk assessment, pesticide residue, exposure to pesticides, food consumption.

\section{INTRODUÇÃO}

As transformações agrícolas no Brasil foram subordinadas às estratégias industrializantes, objetivando principalmente o aumento na produção de alimentos e incremento de capital[1]. O agronegócio, reconhecido como o conjunto das atividades que englobam a produção, armazenamento e distribuição de suprimentos agrícolas, foi responsável no ano de 2015 por 21,46\% do Produto Interno Bruto (PIB), segundo os dados estatísticos de economia agrícola do Ministério da Agricultura Pecuária e Abastecimento (MAPA)[2].

O pacote tecnológico amplamente utilizado no agronegócio envolve, dentre outros aspectos, o uso de agrotóxicos, de modo a combater as pragas e acelerar o crescimento das culturas alimentares. A justificativa para adoção desses compostos na agricultura era erradicar a fome no Brasil e no mundo, por meio do aumento na produção de alimentos [3].

Inicialmente os agrotóxicos foram utilizados como armas químicas de guerra e conquistaram novo mercado, na agricultura, no período pós-guerra[3]. O uso desses insumos foi incentivado por meio de políticas implementadas em todo o mundo, notadamente no Brasil, sendo a Food and Agriculture Organization (FAO) e o Banco Mundial os principais promotores do pacote tecnológico da Revolução Verde no mundo. No Brasil, as políticas adotadas para apoiar a utilização deste pacote tecnológico foram o Sistema Nacional de Crédito Rural (1965) que forçava os agricultores a adquirirem os insumos químicos para a obtenção do crédito, também o Programa Nacional de Defensivos Agrícolas (1975) que possibilitou por meio de incentivos financeiros a criação de empresas nacionais e instalação de subsidiárias de empresas transnacionais de agroquímicos no país $[3,4,5]$.
O Brasil encontra-se entre os maiores consumidores de agrotóxicos do mundo e um dos maiores produtores de commodities de alimentos. Com relação às vendas e comercialização de agrotóxicos no país, os dados do Instituto Brasileiro do Meio Ambiente e dos Recursos Naturais Renováveis (IBAMA) mostram que houve crescimento nas vendas de agrotóxicos de 194,09\% entre os anos de 2000 e 2012[6].

Outra fonte importante de dados no contexto da comercialização deste tipo de insumo é o indicador "uso de agrotóxicos" elaborado pelo Instituto Brasileiro de Geografia e Estatística (IBGE), que busca estimar o aumento no uso de agrotóxicos nas áreas plantadas em determinado período. Este indicador reflete a relação entre a comercialização de agrotóxicos e área plantada (quilograma/hectare/ano), em que as variáveis advêm de dados divulgados pelo IBAMA e/ou do Sistema de Agrotóxicos Fitossanitários (Agrofit), este último visto como mais completo, uma vez que o IBAMA divulga informações referentes apenas a 85 ingredientes ativos (IA) e o Agrofit divulga dados referentes a mais de 400 IA[7,8].

Ao analisar os dados referentes à comercialização de agrotóxicos por área plantada (kg/ha) observa-se o aumento na comercialização de agrotóxicos no país, sem o aumento proporcional da área plantada. A comercialização de agrotóxicos por área plantada (kg/ha) foi de 10,32 em 2007 e alcançou, em 2013, 16,44 kg/ha, enquanto a área plantada (hectare) variou entre 62.338 .730 (2007) e 74.528 .391 (2013). Em se tratando de produtividade, apesar da produção brasileira ter aumentado, dados apontam que o crescimento da quantidade de agrotóxicos utilizados no plantio não necessariamente está associado ao incremento da produtividade, conforme o conjunto de informações que demonstram o aumento no consumo de agrotóxicos na rizicultura 
irrigada de 166\% em 2004 e a produtividade média no período cresceu $10,3 \%\left[{ }^{[8]}\right.$.

Em relação às ocorrências de intoxicações, no período entre 2007 e 2013, é possível verificar uma incidência de intoxicações por agrotóxicos de 3,08/100.000 habitantes em 2007 e em 2013 o resultado 6,23 intoxicações/100.000 habitantes[7,8,9,10]. Esse número maior de notificações em 2013 pode ter relação com o aumento do número de casos de intoxicação, como também a melhora no sistema de informações e na atuação da Vigilância em Saúde, embora ocorram ainda problemas relacionados à subnotificação[ ${ }^{[8]}$.

Reconhece-se a importância da análise do uso dos agrotóxicos à luz do conceito de Segurança Alimentar e Nutricional adotado no Brasil. Este conceito, conforme o artigo 3o da Lei Orgânica de Segurança Alimentar e Nutricional (LOSAN) no 11.346, de 15 de setembro de 2006, consiste ${ }^{[1]}$

$\mathrm{Na}$ realização do direito de todos ao acesso regular e permanente a alimentos de qualidade, em quantidade suficiente, sem comprometer o acesso a outras necessidades essenciais, tendo como base práticas alimentares promotoras de saúde que respeitem a diversidade cultural e que sejam ambiental, cultural, econômica e socialmente sustentáveis.

Existem numerosas evidências que atribuem a exposição aos agrotóxicos a vários efeitos adversos à saúde humana e ao meio ambiente. A exposição aos agrotóxicos pode ser de forma crônica ou aguda, ambas com impactos para a saúde pública e os grupos mais vulneráveis aos efeitos adversos desses compostos são as crianças, trabalhadores rurais e população dos países em desenvolvimento[ ${ }^{[12]}$.

De modo geral, a intoxicação aguda por agrotóxicos resulta em efeitos e/ou sintomas como: fraqueza, cólicas abdominais, vômitos, espasmos musculares, convulsões, irritações das conjuntivas, dor de cabeça, dificuldade respiratória, perda de apetite, sangramento nasal, dentre outros; a intoxicação crônica pode ocasionar efeitos neurotóxicos retardados, alterações cromossomiais, dermatites de contato, lesões hepáticas, arritmias cardíacas, lesões renais, neuropatias periféricas, alergias, asma brônquica, Doença de Parkinson, cânceres, teratogêneses, perda auditiva e desregulação endócrina ${ }^{[12,13] .}$

A lei que define os agrotóxicos no Brasil é a no 7.802, de 11 de julho de 1989, e especifica, entre outros aspectos, que é de responsabilidade da ANVISA (Agência Nacional de Vigilância Sanitária) estabelecer o Limite Máximo de Resíduo (LMR), a Ingestão Diária Aceitável (IDA) dos ingredientes ativos e a classificação toxicológica dos produtos formulados; o Ministério da Agricultura, Pecuária e Abastecimento (MAPA) possui a atribuição de avaliar a eficiência agronômica e aprovação do rótulo do produto; e o Instituto Brasileiro do Meio Ambiente e dos Recursos Naturais Renováveis (IBAMA) avalia o impacto do agroquímico no meio ambiente e em outros organismos vivos ${ }^{[1,15]}$.

Com intuito de garantir a segurança alimentar, uma das etapas da análise de risco utiliza o cálculo da Ingestão Diária Máxima Teórica (IDMT), de modo a obter a estimativa de ingestão de resíduos de agrotóxicos e avaliar a exposição a esses compostos. Para o cálculo são utilizados dados do Limite Máximo de Resíduos (LMR), quantidade consumida da cultura alimentar e peso corpóreo dos indivíduos, o resultado é então comparado a Ingestão Diária Aceitável (IDA), não devendo, portanto, ultrapassar este parâmetro, o que significa, ao menos em princípio, que não haverá implicações adversas na saúde ${ }^{[16,17]}$.

Os resultados obtidos por meio do cálculo da IDMT podem ainda serem analisados no âmbito da classificação toxicológica (grau de toxicidade) dos agrotóxicos, proposta pela ANVISA, obtida de resultados de estudos toxicológicos agudos (Quadro 1). Esta classificação segue a Portaria no 3 , do Ministério da Saúde de 16 de janeiro de 1992 e o Guia para elaboração de rótulo e bula de agrotóxicos, afins e preservativos de madeira. A Portaria considera a atuação da substância em animais (ratos) de prova e infere os riscos para a saúde humana ${ }^{[18,19]}$. 
Quadro 1. Classes toxicológicas e suas respectivas cores de faixas

\begin{tabular}{|c|c|c|c|}
\hline Classe & Toxicidade & Cor da faixa de rótulo ou bula & Pantone Matching System (PMS) \\
\hline I & $\begin{array}{l}\text { Extremamente tóxicos } \\
\left(\mathrm{DL}_{50}<40 \mathrm{mg} / \mathrm{kg}\right)\end{array}$ & Faixa vermelha & Vermelho PMS Red 199 C \\
\hline II & $\begin{array}{c}\text { Muito tóxicos } \\
\left(\mathrm{DL}_{50}-40 \text { a } 400 \mathrm{mg} / \mathrm{kg}\right)\end{array}$ & Faixa amarela & Amarelo PMS Yellow C \\
\hline III & $\begin{array}{l}\text { Medianamente tóxicos } \\
\text { (DL } 50 \text { - } 400 \text { a } 4000 \mathrm{mg} / \mathrm{kg} \text { ) }\end{array}$ & Faixa azul & Azul PMS Blue 293 C \\
\hline IV & $\begin{array}{c}\text { Pouco tóxicos } \\
\left(\mathrm{DL}_{50}>4000 \mathrm{mg} / \mathrm{kg} \text { ) }\right.\end{array}$ & Faixa verde & Verde PMS Green 347 C \\
\hline
\end{tabular}

Objetivando minimizar ou eliminar o risco de exposição da população aos agrotóxicos, além da avaliação rigorosa do risco do IA, deve haver o monitoramento referente à utilização do composto[20]. Deste modo, existe no Brasil desde 2003 o Programa Nacional de Monitoramento de Resíduos de Agrotóxicos em Alimentos (PARA), coordenado pela ANVISA em conjunto com as Vigilâncias Sanitárias (VISA) e com os Laboratórios Centrais de Saúde Pública (Lacen), implementado por meio da Resolução no 119, de 19 de maio de 2003, que visa o controle contínuo de resíduos de agrotóxicos em alimentos de origem vegetal[21].

Os resultados dos alimentos analisados no período de 2013-2015 (25 alimentos de origem vegetal - 12.051 amostras) revelaram que 19,7\% das amostras estavam insatisfatórias, por apresentarem resíduos de agrotóxicos não autorizados $(18,3 \%)$ ou acima do $\operatorname{LMR}(3 \%)^{[22]}$.

Face ao exposto, uma vez que a exposição humana aos agrotóxicos é um problema de saúde pública, o presente estudo objetivou estimar a ingestão dos resíduos de agrotóxicos a partir da dieta habitual de escolares e deste modo, contribuir com informações que subsidiem ações de prevenção.

\section{MÉTODOS}

Trata-se de um estudo transversal que envolve elaboração de estimativa de ingestão de resíduos de agrotóxicos potencialmente contidos na dieta habitual de escolares. O total de crianças avaliadas e variáveis como idade, sexo, peso, altura, índice de massa corporal (IMC) e quantidade (medidas caseiras) dos alimentos consumidos (dentro e fora do domicilio) diariamente foram obtidos do conjunto de dados original intitulado "Programa de alimentação escolar: perfil dos beneficiários, qualidade e atuação de gestores e da comunidade de Guariba"[23]. A pesquisa que viabilizou a coleta de dados recebeu aprovação (protocolo no 99) do Comitê de Ética em Pesquisa com Seres Humanos da Escola Superior de Agricultura "Luiz de Queiroz" (ESALQ - Piracicaba, SP), Universidade de São Paulo.

$O$ estudo com os dados originais analisa, entre outros aspectos, a alimentação escolar nas unidades de ensino públicas do município de Guariba (São Paulo), situado no Estado de São Paulo, na região administrativa de Ribeirão Preto. Esta região possui modernos complexos agroindustriais no setor canavieiro, além de beneficiadoras de café, amendoim e soja, frigoríficos, indústrias alimentícias de derivados de leite, indústrias de ração, fertilizantes e várias indústrias de suco de laranja ${ }^{[24,25,26] .}$

As análises envolveram os dados relativos à amostra composta por 341 alunos de ambos os sexos, com idades entre 7 e 16 anos, matriculados em seis escolas da rede municipal de ensino da cidade de Guariba (São Paulo). O método de seleção dos alunos participantes no estudo original foi sorteio em sala de aula e na reunião de pais, por meio da lista de frequência. Adotou-se também o critério de participação de $20 \%$ da totalidade de alunos divididos nos estratos etários de 7 a 9 anos, 10 a 12 anos e acima de 13 anos.

Foram excluídos os alunos que por algum motivo não puderam ser pesados e medidos e também aqueles que tinham alguma doença crônica. 
A quantificação da exposição (estimada) ao agrotóxico na dieta foi obtida por meio da equação definida pelo somatório do produto da concentração do agroquímico pelo consumo do alimento, dividido pelo peso corpóreo [27]. A Ingestão Diária Máxima Teórica (IDMT) é, portanto, o somatório do limite máximo de resíduos (LMR), em $\mathrm{mg} / \mathrm{kg}$, multiplicando-se pelo consumo do alimento (C), em $\mathrm{kg} /$ dia e comparada à ingestão diária aceitável (IDA), em $\mathrm{mg} / \mathrm{kg}$ peso corpóreo/dia e expressa em \% IDA.

O consumo de alimentos foi obtido por meio de dois recordatórios de 24 horas [23]. As preparações foram desmembradas em proporções de ingredientes, a partir de uma receita padronizada e construída uma tabela que relacionava o código do aluno aos alimentos e/ou preparações consumidas e suas respectivas quantidades em gramas utilizando um banco de dados relacional Oracle Database Release 11.2.0.1.0, PL/SQL (Procedural Language/Structured Query Language) 8.0.3.1510.

As quantidades dos alimentos constituintes das preparações foram obtidas por meio das publicações de Pinheiro et al. (2008) ${ }^{[28]}$ e Fisberg et al. (2002) ${ }^{[29] .}$

Os alimentos processados foram correlacionados ao(s) seu(s) respectivo(s) alimento(s) in natura ou ao(s) principal(is) ingrediente(s) in natura contido(s) no produto, com proporções que respeitassem a legislação brasileira vigente ou informações do rótulo do produto. Os queijos, requeijão, leite condensado, creme de leite, iogurte e manteiga, foram considerados como leite; para a linguiça e presunto assumiu-se como ingrediente principal a carne suína; para a margarina considerou-se o óleo de soja como principal ingrediente; no caso da massa para lasanha e macarrão considerou-se o ingrediente farinha de trigo; para a salsicha adotou-se a composição das carnes bovina, suína e de frango, além dos miúdos ${ }^{[30]}$.

Os alimentos in natura, ou seja, aqueles em que o consumo não possui nenhuma forma de processamento ou preparo, foram diretamente considerados para a análise. Os vários tipos de cortes e modos de preparo das carnes foram agrupados conforme o animal de origem e designados como "carne bovina", "carne suína" ou "carne de frango".
Como critérios de exclusão para determinadas preparações reportadas, considerou-se o fato de não haver receita padrão ou formulação referenciada, não conter ingrediente com LMR e IDA estabelecidos ou ainda no caso dos produtos cujo principal ingrediente ser o açúcar, o produto constar como diet ou zero açúcar.

Para cada alimento consumido pelos escolares considerou-se que todos continham resíduos de agrotóxicos no Limite Máximo de Resíduo (LMR) obtido(s) da base de dados da ANVISA, disponibilizados nas monografias autorizadas, atualizadas até o mês de maio de 2016[31]. Os alimentos para os quais não há dados relativos aos valores de LMR publicados no Brasil, especialmente os de origem animal, foi adotada a base de dados do Codex Alimentarius[32]. Os parâmetros de Ingestão Diária Aceitável (IDA) foram obtidos das monografias autorizadas de cada ingrediente ativo (IA) publicadas no site da ANVISA[31]. Para os ingredientes ativos autorizados no Brasil que não apresentavam valores de IDA estipulados no país foram adotados os índices do Codex Alimentarius, Environmental Protection Agency (EPA) e do governo da Austrália[32,33,34].

Os compostos que não dispunham de dados de IDA registrados por nenhuma dessas agências ou não são autorizados no Brasil foram excluídos das análises.

A descrição detalhada dos valores propostos pela totalidade das agências pode ser consultada no trabalho de Meira (2016) [35].

Visando identificar a relação entre os vários limites estabelecidos pelas distintas instituições, foi elaborada análise de correlação. Verificou-se que todas as correlações (duas a duas) são estatisticamente significativas ao nível de 1\%. Destaca-se que a correlação mais alta $(0,93703)$ ocorre entre os valores estabelecidos pela ANVISA e Codex.

Foram construídas tabelas com os dados no Microsoft Excel, versão 2007 e utilizando o software Statistical Analysis System - SAS ${ }^{\circledR}$, versão 9.3[36], para cada aluno calculou- se a IDMT e análises estatísticas foram obtidas, como a estimativa média de ingestão de cada composto, a mediana de ingestão e o valor máximo de ingestão por aluno, permitindo analisar os casos nos quais a IDMT ultrapassou os valores de 
IDA especificados pelas agências adotadas neste estudo.

\section{RESULTADOS}

As análises de estimativa de ingestão de agrotóxicos foram conduzidas utilizando dados antropométricos individuais dos 341 alunos (48,97\% do sexo masculino e $51,03 \%$ do sexo feminino) que integram a amostra. $\mathrm{O}$ estado nutricional (tendo por base intervalos de escore $Z$ do IMC) reportado no estudo original indica que a maioria dos escolares $(52,71 \%)$ foi classificada como eutrófica e parcela importante $(46,35 \%)$ com excesso de peso. A maior proporção de obesidade ocorreu no intervalo de idade de 8 a 13 anos[23].
No tocante a situação econômica destaca-se que $90,88 \%$ dos escolares integravam famílias com rendimentos per capita inferiores a $\mathrm{R} \$ 600,00$ (valor do salário mínimo na época da pesquisa $=\mathrm{R} \$ 678,00)$. Mais da metade $(51,25 \%)$ era beneficiária de programa de transferência de renda, recebendo valores que variaram entre $R \$ 100$ e $R \$ 200[23]$.

Com base nos resultados obtidos por meio do cálculo da Ingestão Diária Máxima Teórica (IDMT) foi possível selecionar os 10 agrotóxicos que apresentaram os maiores valores médios de ingestão (estimada), conforme mostra a Tabela 1.

Tabela 1. Ingestão (média) diária estimada dos 10 agrotóxicos potencialmente contidos na dieta habitual dos escolares e as respectivas classes toxicológicas. Guariba, SP, 2013

\begin{tabular}{lccc}
\hline \multicolumn{1}{c}{ Agrotóxicos } & $\begin{array}{c}\text { Média de ingestão } \\
(\mathrm{mg} / \mathrm{kg} / \mathrm{dia})\end{array}$ & Desvio Padrão (dp) & Classe toxicológica \\
\hline Hidrazida Malêica & 0,109725 & 0,0990 & IV \\
Malationa & 0,102590 & 0,0604 & III \\
Pirimifós-metílico & 0,052565 & 0,0304 & III \\
Captana & 0,033736 & 0,0344 & IV \\
Etofenproxi & 0,021397 & 0,0136 & IV \\
Clorotalonil & 0,019895 & 0,0120 & III \\
Brometo de Metila & 0,016361 & 0,0476 & I \\
Imazamoxi & 0,015391 & 0,0103 & II \\
Tiofanato - Metílico & 0,015384 & 0,0122 & IV \\
Tiabendazol & 0,013489 & 0,0177 & IV \\
\hline
\end{tabular}

Ao analisar os resultados apresentados na tabela 1, verifica-se que o brometo de metila, composto pertencente à classe toxicológica I, é considerado extremamente tóxico. Este composto é da classe dos inseticidas, formicidas, fungicidas, herbicidas e nematicidas, aplicado como fumigante nas culturas de abacate, abacaxi, ameixa, café, castanha-decaju, castanha-do-Pará, citros, damasco, maçã, mamão, manga, marmelo, melancia, melão, morango, nectarina, pêra, pêssego e uva[31]. Conforme a Instrução Normativa Conjunta no 2, de 14 de dezembro de 2015, Art. 1o fica autorizado o uso de brometo de metila no Brasil exclusivamente em tratamento fitossanitário com fins quarentenários nas operações de importação e de exportação, na forma desta Instrução Normativa Conjunta[37].
O Imazamoxi, herbicida de classificação toxicológica classe II (muito tóxico) também está presente (quantidade elevada de ingestão), sendo autorizado para aplicação em pós-emergência das plantas infestantes nas culturas de amendoim, arroz, canola, feijão, girassol, soja e trigo[31].

Os resultados da comparação entre as quantidades (valores medianos e máximos) de ingestão dos agrotóxicos e a Ingestão Diária Aceitável (IDA) divulgadas pelas quatro agências (ANVISA, EPA, Codex Alimentarius e governo da Austrália) estão reunidos na Tabela 2. 
Tabela 2. Consumo (estimado) de agrotóxicos, pelos escolares, que superam os parâmetros de Ingestão Diária Aceitável (IDA), definidos pelos órgãos reguladores. Guariba, SP, 2013

\begin{tabular}{lcccc}
\hline \multicolumn{1}{c}{ Ingestão (mg/dia) } & ANVISA & EPA & CodexAlimentarius & $\begin{array}{c}\text { Governo da } \\
\text { Austrália }\end{array}$ \\
\hline Mediana >IDA & 9 & 5 & 4 & 15 \\
Valor Máximo >IDA & 58 & 45 & 43 & 60 \\
Valor Máximo < IDA & 145 & 24 & 92 & 147 \\
Indeterminada & 60 & 198 & 133 & 50 \\
\hline
\end{tabular}

Nota: a categoria Indeterminada significa que não há parâmetro de IDA estabelecido.

Os valores das medianas de ingestão mostram que $9(3,31 \%)$ do total de agrotóxicos analisados (272) ultrapassaram o limite da ANVISA; $5(1,82 \%)$ da agência EPA; $4(1,47 \%)$ do Codex Alimentarius e 15 (5,51\%) do governo da Austrália, sugerindo exposição a esses compostos e risco aumentado dos impactos negativos ocasionados por essas substâncias na saúde dos indivíduos. Com relação aos valores da ingestão máxima, 58 (21,32\%) dos agrotóxicos analisados superaram os limites estabelecidos pela ANVISA, 45 $(16,54 \%)$ da agência EPA, $43(15,81 \%)$ do Codex Alimentarius e $60(22,06 \%)$ do governo da Austrália.

Os agrotóxicos que superaram (valores medianos) o parâmetro IDA da ANVISA estão reunidos na Tabela 3.

Tabela 3. Consumo estimado de agrotóxicos (valores medianos) que superam a ingestão diária aceitável (IDA) da ANVISA. Guariba, SP, 2013

\begin{tabular}{|c|c|c|c|}
\hline Composto & Mediana (mg/dia) & IDA (mg/kg de peso corpóreo) & Classe toxicológica \\
\hline Acefato & 0,002949 & 0,0012 & $\overline{\mathrm{III}}$ \\
\hline Carbofurano & 0,002335 & 0,0020 & $\mathrm{I}$ \\
\hline Diazinona & 0,008200 & 0,0020 & II \\
\hline Diquate & 0,003271 & 0,0020 & II \\
\hline Fentina & 0,000845 & 0,0005 & II \\
\hline Fipronil & 0,001639 & 0,0002 & II \\
\hline Pirimifós-metílico & 0,046213 & 0,0300 & III \\
\hline Terbufós & 0,000207 & 0,0002 & I \\
\hline Tetraconazol & 0,006229 & 0,0050 & II \\
\hline
\end{tabular}

As análises relacionando os nove compostos em que a mediana de ingestão ultrapassou a IDA da ANVISA com a respectiva classe toxicológica mostra que $2(22,22 \%)$ são da classe toxicológica I (extremamente tóxicos), 5 (55,56\%) da classe II (muito tóxicos), $2(22,22 \%)$ da classe III (medianamente tóxicos) e nenhum da classe IV (pouco tóxicos), indicando que $\mathrm{O}$ alto consumo de alimentos contaminados por esses compostos pode representar risco à saúde ${ }^{[38]}$.

O carbofurano, agrotóxico pertencente à classe toxicológica I, utilizado como inseticida, cupinicida, acarida e nematicida é indicado para aplicação no solo nas culturas de algodão, amendoim, arroz, banana, batata, café, cana-de-açúcar, cenoura, feijão, fumo, milho, repolho tomate e trigo, além da aplicação em sementes de algodão, arroz, feijão, milho e trigo.

Outro composto representante da classe toxicológica I, ou seja, extremamente tóxico, o terbufós, em que a estimativa da mediana de ingestão extrapolou os limites de ingestão da ANVISA, é um organofosforado que pode ser aplicado no solo nas culturas de algodão, amendoim, banana, café, cana-deaçúcar, feijão e milho[ ${ }^{[31]}$. 
Os organofosforados possuem ação tóxica baseada na inibição da enzima acetilcolinesterase e a toxicidade crônica é relacionada aos efeitos neurotóxicos ${ }^{[39,40]}$. Demais representantes deste grupo químico que tiveram a mediana de ingestão acima do preconizado pela ANVISA foram o acefato e a diazinona, pertencentes às classes toxicológicas III e II, respectivamente.

Vale ressaltar que o acefato, a diazinona e o fipronil foram reconhecidos no estudo de McKinlay et al. (2008)[41], como agrotóxicos que associam-se à desregulação endócrina ${ }^{[41,42]}$. A desregulação endócrina pode ocasionar alterações no desenvolvimento, distúrbios psicomotores, diabetes, obesidade, entre outros ${ }^{[42,43,44,45,46]}$.

A quantidade de agrotóxicos cuja estimativa de ingestão (valores medianos) superou os limites estabelecidos pelo governo da Austrália foram ainda maiores (tabela 4), sendo identificados 15 compostos e desse total $(n=15), 3(20 \%)$ pertencem a classe toxicológica I, $8(53,33 \%)$ a classe II e $4(26,67 \%)$ a classe III.

Entre os 15 agrotóxicos, o lambda-cialotrina, piretróide da classe dos inseticidas, considerado medianamente tóxico, é listado como possível desregulador endócrino pela Pesticide Action Network UK (2001) [47], Ratnasoorya et al. (2002)[48] e Göettlich (2016) ${ }^{[49]}$, podendo atuar como antagonista ou agonista de um hormônio.

Pode ser utilizado em uma ampla variedade de culturas alimentares, especialmente abacate, abacaxi, abóbora, abobrinha, agrião, alface, alho, alho-porró, amendoim, arroz, aveia, batata, batata-doce, berinjela, beterraba, brócolis, café, cacau, cana-de-açúcar, canola, cará, cebola, cebolinha, centeio, cevada, chuchu, citros, coentro, couve, couve-flor, ervilha, feijão, figo, gengibre, gergelim, grão-de-bico, inhame, jiló, kiwi, lentilha, mamão, mandioca, mandioquinha-salsa, manga, maracujá, melancia, melão, milho, morango, nabo, pepino, pimentão, quiabo, rabanete, repolho, romã, soja, tomate, trigo e uva. Também pode ser utilizado nas culturas de arroz, cevada, milho e trigo armazenados[31].
Tabela 4. Consumo estimado de agrotóxicos (valores medianos) que supera a ingestão diária aceitável (IDA) do governo da Austrália. Guariba, SP, 2013

\begin{tabular}{lccc}
\hline \multicolumn{1}{c}{ Composto } & $\begin{array}{c}\text { Mediana } \\
(\mathrm{mg} / \mathrm{dia})\end{array}$ & $\begin{array}{c}\text { IDA }(\mathrm{mg} / \mathrm{kg} \\
\text { de peso } \\
\text { corpóreo }\end{array}$ & $\begin{array}{c}\text { Classe } \\
\text { toxicológica }\end{array}$ \\
\hline Clorpirifós & 0,004986 & 0,00300 & $\mathrm{II}$ \\
Diazinona & 0,008200 & 0,00100 & II \\
Dimetoato & 0,001530 & 0,00100 & I \\
$\begin{array}{l}\text { Diquate } \\
\text { Etiona }\end{array}$ & 0,003271 & 0,00200 & II \\
Fenamifós & 0,001912 & 0,00100 & II \\
Fipronil & 0,000138 & 0,00010 & I \\
Lambda- & 0,001639 & 0,00020 & II \\
Cialotrina & 0,006329 & 0,00100 & III \\
Mancozebe & 0,006233 & 0,00600 & III \\
Pirimifós- & & & III \\
metílico & 0,046213 & 0,02000 & \\
Profenofós & 0,001289 & 0,00010 & II \\
Propinebe & 0,004130 & 0,00050 & III \\
Protiofós & 0,000807 & 0,00010 & II \\
Terbufós & 0,000207 & 0,00020 & I \\
Tetraconazol & 0,006229 & 0,00400 & II \\
\hline
\end{tabular}

\section{DISCUSSÃO}

O estudo apresenta resultados importantes relativos à estimativa da exposição aos agrotóxicos a partir da dieta de grupo de crianças, considerado um dos mais vulneráveis aos efeitos adversos dos agrotóxicos, além de estar em acordo com o preconizado pela World Health Organization - WHO (2005), que considera como situação ideal de estimativa da exposição aos agrotóxicos aquela na qual são adotados os dados de consumo individual associado ao peso corpóreo do indivíduo em conjunto com as características socioeconômicas e demográficas ${ }^{[27,50]}$.

Cabe confrontar os achados com as lacunas de conhecimento relacionadas à multiexposição aos agrotóxicos, haja vista que a maioria das avaliações de risco é condicionada a apenas um princípio ativo ou produto formulado.

Os parâmetros utilizados nesse estudo para o cálculo da IDMT, por exemplo, a IDA tem por base estudos experimentais envolvendo animais de laboratório, extrapolando-se os resultados para os humanos, porém, não confere proteção real da saúde, especialmente se for considerada a exposição crônica, advinda das exposições combinadas, em pequenas doses, durante longo período de tempo ${ }^{[51]}$. 
O contexto da população analisada neste estudo, exposta ao modelo agrícola vigente, está associado a uma vulnerabilidade frente aos efeitos nocivos dos agrotóxicos, conforme pontuado anteriormente, em decorrência da imaturidade fisiológica, além do perfil socioeconômico mostrado, no qual mais de $90 \%$ dos alunos podem ser classificados como pobres.

A partir dos resultados obtidos por meio do cálculo da IDMT, destacam-se os casos em que a mediana de ingestão superou a IDA preconizada pela ANVISA (acefato, carbofurano, diazinona, diquate, fentina, fipronil, pirimifós-metílico, terbufós e tetraconazol). A maioria desses compostos possui classificação toxicológica II (muito tóxico), indicando potencial risco à saúde dos escolares. São compostos, na maioria dos casos, autorizados para aplicação em ampla variedade de culturas alimentares, sendo o acefato, diazinona e fipronil relacionados à desregulação endócrina, podendo ocasionar, dentre outros danos, alterações no desenvolvimento, risco crítico principalmente quando se trata da faixa etária analisada nesta pesquisa.

O carbofurano, após reavaliação toxicológica pela ANVISA, teve seu uso proibido recentemente. As análises concluíram que o uso regular desse ingrediente resulta em níveis de resíduos em alimentos e na água, e por meio da ingestão pela população pode ocasionar efeitos neurotóxicos e toxicidade para o desenvolvimento de seres humanos[52]. Entre os demais ingredientes ativos em que a mediana de ingestão superou os limites da ANVISA, o acefato, diazinona, pirimifós-metílico e o terbufós integram a classe química dos organofosforados (OPs), cuja categoria está diretamente relacionada à inibição da enzima acetilcolinesterase (AChE) ${ }^{[11}$.

O acefato também é considerado pela ANVISA um IA comprovadamente de alto grau de toxicidade aguda e que ocasiona problemas de desregulação hormonal, neurológicos, reprodutivos e câncer, sendo proibido em vários países, porém, o seu uso foi mantido no Brasil em decorrência das pressões do setor agrícola[51]. Após finalização do processo de reavaliação pela ANVISA, a resolução - RDC 45/2013 detalha que o acefato será mantido com restrições, especialmente no que se refere ao modo de aplicação e culturas autorizadas ${ }^{[53]}$.
A diazinona, embora tenha sido classificada pela International Agency for Research on Cancer - IARC como provável carcinógeno em humanos e banida da União Européia, teve seu uso mantido no Brasil.

Reforçando a situação preocupante da potencial exposição dos escolares a esses compostos, os resultados dos agrotóxicos que tiveram a ingestão máxima (estimada) acima dos limites estabelecidos foram ainda maiores (58 agrotóxicos apresentaram valor de ingestão máxima superior ao parâmetro IDA da ANVISA).

A comparação dos resultados do presente estudo com os valores indicados pelas 4 agências foi adotada motivada pelo fato que cada órgão regulador utiliza uma metodologia específica para delineamento do parâmetro, além das diferenças no quesito quantidade de agrotóxicos sem IDA estabelecido (indeterminado). A ANVISA possui 60 agrotóxicos dos 272 analisados sem IDA estabelecido, a agência EPA 198, o Codex Alimentarius 133 e o Governo da Austrália 50. Examinando os valores registrados pelas 4 agências foi possível identificar 40 substâncias que foram registradas simultaneamente.

A proteção da saúde pública e do meio ambiente devem ser prioridades. No entanto, o que se observa é o atendimento dos interesses do agronegócio, muitas vezes em detrimento da Segurança Alimentar e Nutricional, com a justificativa do impacto "positivo" deste setor na economia do país, desestimulando as tentativas de investimento na agricultura familiar, agroecologia e produção orgânica de alimentos. Também é preciso analisar a limitada abrangência da fiscalização por parte dos órgãos responsáveis, embora o Programa Nacional de Monitoramento de Resíduos de Agrotóxicos (PARA) tenha sido um avanço a partir de 2003, sofre com a escassez de recursos financeiros e recurso humano, além dos problemas de infraestrutura dos laboratórios credenciados. O programa contempla apenas alimentos de origem vegetal.

Torna-se incoerente o Brasil, considerado um dos maiores consumidores de agrotóxicos do mundo, com expressiva parcela da população exposta à vulnerabilidade econômica e social, não garantir a atuação de um programa de monitoramento eficaz do uso desses ingredientes. A título de exemplo, o Programa de Monitoramento da Dinamarca existe 
desde 1983, com inclusão do monitoramento de produtos de origem animal e comida para bebês.

As diferenças nas quantidades de amostras de alimentos analisadas no Brasil também são expressivas quando comparadas ao Programa de Monitoramento dos Estados Unidos (EUA), que em 2014 analisou 10.619 amostras, incluindo produtos utilizados por crianças e lactentes, enquanto no Brasil em 2012, foram examinadas 1.665 amostras de vegetais ${ }^{[54]}$.

As análises envolvidas no presente estudo podem subsidiar as discussões no processo de autorização de novos registros de agrotóxicos ou inclusão de novas culturas de alimentos e reavaliações das autorizações já existentes, considerando a estreita relação entre o consumo, pela população brasileira, notadamente a infantil, de determinados alimentos, que integram a alimentação básica e as substâncias de elevada toxicidade utilizadas no sistema de produção desses alimentos.

\section{REFERÊNCIAS}

[1] Leite SP. Estado, padrão de desenvolvimento e agricultura: o caso brasileiro. Estudos, Sociedade e Agricultura [Internet]. 2005 [acesso em 2016 fev 02]; 13(2). Disponível em: http://r1.ufrrj.br/esa/V2/ojs/index.php/esa/article/view/265

[2] Brasil. Ministério da Agricultura, Pecuária e Abastecimento. Estatísticas e dados básicos de economia agrícola [Internet]. 2016 [acesso em 2017 nov 23]. Disponível em: http://www.agricultura.gov.br/agroestatisticas/estatisticas-e-dadosbasicos-de-economia-agricola/estatisticas-e-dados-basicos-deeconomia-agricola-abril-2016.pdf/view

[3] Londres F. Agrotóxicos no Brasil - um guia para ação em defesa da vida [Internet]. 2011 [acesso em 2017 nov 23]. Disponível em:

http://www.agroecologia.org.br/files/importedmedia/agrotoxicos -no-brasil-um-guia-para-acao-em-defesa-da-vida.pdf

[4] Pelaez V, Terra FHB, Silva LR. A regulamentação dos agrotóxicos no Brasil: entre o poder de mercado e a defesa da saúde e do meio ambiente. Rev Econ [Internet]. 2010 [acesso em 2016 mar 01]; 36(1). Disponível em: http://ojs.c3sl.ufpr.br

[5] Silva JM, Novato-Silva E, Faria HP, Pinheiro TMM. Agrotóxico e trabalho: uma combinação perigosa para a saúde do trabalhador rural. Cien. Saude Colet. [Internet]. 2005 [acesso em 2016 mar 01]; 10(4). Disponível em: http://www.scielo.br

[6] Brasil. Ministério do Meio Ambiente. Instituto Brasileiro do Meio Ambiente e dos Recursos Naturais Renováveis (IBAMA). Boletim de comercialização de agrotóxicos e afins - histórico de vendas 2000-2012 [Internet]. 2013 [acesso em 2017 nov 23]. Disponível em: http://www.ibama.gov.br/agrotoxicos/relatoriosde-comercializacao-de-agrotoxicos

[7] Instituto Brasileiro de Geografia e Estatística (IBGE). Indicadores de desenvolvimento sustentável. Rio de Janeiro [Internet]. 2015 [acesso em 2018 fev 02]. Disponível em: https://biblioteca.ibge.gov.br/visualizacao/livros/liv94254.pdf

[8] Brasil. Ministério da Saúde (MS). Relatório nacional de vigilância em saúde de populações expostas a agrotóxicos [Internet]. 2016 [acesso em 2016 out 12]. Disponível em: http://bvsms.saude.gov.br/bvs/publicacoes/agrotoxicos_otica_sis tema_unico_saude_v1_t.1.pdf

[9] Sistema de Informação de Agravos de Notificação (Sinan) [Internet]. 2017 [acesso em 2017 nov 23]. Disponível em: http://portalsinan.saude.gov.br/

[10] Brasil. Ministério da Agricultura, Pecuária e Abastecimento. AGROFIT: Sistema de Agrotóxicos Fitossanitários. Brasília: Ministério da Agricultura, Pecuária e Abastecimento; 2003.

[11] Brasil. Lei no 11.346, de 15 de setembro de 2006. Cria o Sistema Nacional de Segurança Alimentar e Nutricional - SISAN com vistas em assegurar o direito humano à alimentação adequada e dá outras providências [Internet]. Diário Oficial da União 15 set 2006 [acesso em 2017 nov 23]. Disponível em: http://www.planalto.gov.br/ccivil_03/_Ato20042006/2006/Lei/L11346.htm

[12] Jardim ANO, Caldas ED. Exposição humana a substâncias químicas potencialmente tóxicas na dieta e os riscos para a saúde. Quim. Nova. 2009;32(7): 1898-1909.

[13] Natural Resources Defense Council (NRDC). Our children at risk: the five worst environmental threats to their health [Internet]. 1997 [acesso em 2016 mar 11]. Disponível em: http://www.nrdc.org/health/kids/ocar/chap5.asp

[14] Brasil. Decreto no 4.074, de 04 de janeiro de 2002. Regulamenta a Lei no 7.802, de 11 de julho de 1989, que dispõe sobre a pesquisa, a experimentação, a produção, a embalagem e rotulagem, o transporte, o armazenamento, a comercialização, a propaganda comercial, a utilização, a importação, a exportação, o destino final dos resíduos e embalagens, o registro, a classificação, o controle, a inspeção e a fiscalização de agrotóxicos, seus componentes e afins, e dá outras providências [Internet]. Diário Oficial da União 08 jan 2002 [acesso em 2017 nov 23]. Disponível em: http://www.planalto.gov.br

[15] Brasil. Lei no 7.802, de 11 de julho de 1989. Dispõe sobre a pesquisa, a experimentação, a produção, a embalagem e rotulagem, o transporte, o armazenamento, a comercialização, a propaganda comercial, a utilização, a importação, a exportação, o destino final dos resíduos e embalagens, o registro, a classificação, o controle, a inspeção e a fiscalização de agrotóxicos, seus componentes e afins, e dá outras providências [nternet]. Diário Oficial da União 11 jul 
1989 [acesso em 2017 nov 23]. Disponível em: http://www.planalto.gov.br/ccivil_03/leis/L7802.htm

[16] Amaral LMS. Análise crítica dos valores de ingestão diária estabelecidos para praguicidas no Brasil, em relação as agências internacionais e a Agência de Proteção Ambiental americana, e suas implicações na avaliação do risco [Internet]. São Paulo: Universidade de São Paulo; 2013 [acesso em 2019 mar 13]. Disponível em file://C:/Users/Administrator/Downloads/Dissertacao_de_mes trado_Ligia_Mesquita_Sampaio_do_Amaral.pdf

[17] World Health Organization (WHO); International Programme on Chemical Safety (IPCS). IPCS Risk Assessment Terminology. Genebra, Switzaerland: United Nations Environmental Programme, International Labour Organization, World Health Organization [Internet]. 2004 [acesso em 2016 mar 09]. Disponível em: http://www.who.int

[18] Brasil. Ministério da Saúde (MS). Agência Nacional de Vigilância Sanitária. Portaria no 3, de 16 de janeiro de 1992. Ratifica os termos das "diretrizes e orientações referentes à autorização de registros, renovação de registro e extensão de uso de produtos agrotóxicos e afins - oo 1, de 09 de dezembro de 1991" [Internet]. Diário Oficial da União 16 jan 1992 [acesso em 2019 mar 13]. Disponível em: http://bvsms.saude.gov.br

[19] Brasil. Ministério da Saúde (MS). Agência Nacional de Vigilância Sanitária. Guia para elaboração de rótulo e bula de agrotóxicos, afins e preservativos de madeira. Guia no 12, versão 1 [Internet]. 2018 [acesso em 2019 mar 12]. Disponível em: http://portal.anvisa.gov.br/documents

[20] Godoy RCB, Oliveira MI. Agrotóxicos no Brasil: processo de registro, riscos à saúde e programas de monitoramento. Cruz das Almas: Embrapa Mandioca e Fruticultura Tropical [nternet]. 2004 [acesso em 2016 fev 11]. Disponível em: https://www.infoteca.cnptia.embrapa.br/bitstream/doc/653905/1 /documento134.pdf

[21] Brasil. Ministério da Saúde (MS). Agência Nacional de Vigilância Sanitária (ANVISA). Resolução no 119, de 19 de maio de 2003. Cria o Programa de Análise de Resíduos de Agrotóxicos em Alimentos - PARA [nternet]. Diário Oficial da União 22 maio 2003 [acesso em 2016 dez 02]. Disponível em: http://portal.anvisa.gov.br/documents

[22] Brasil. Ministério da Saúde (MS). Agência Nacional de Vigilância Sanitária (ANVISA). Gerência Geral de Toxicologia. Programa de Análise de Resíduos de Agrotóxicos em Alimentos (PARA) - relatório das análises de amostras monitoradas no período de 2013 a 2015 [Internet]. 2016 [acesso em 2016 dez 02]. Disponível em: http://portal.anvisa.gov.br

[23] Amistá MJM. Programa de alimentação escolar: perfil dos beneficiários, qualidade e atuação de gestores e da comunidade de Guariba [dissertação na internet]. Piracicaba: Escola Superior de Agricultura "Luiz de Queiroz” Universidade de São Paulo; 2013 [citado em 2019 mar 13]. Disponível em: http://www.teses.usp.br
[24] Andrade MC. Modernização e pobreza: a expansão da agroindústria canavieira e seu impacto ecológico e social. São Paulo: Editora da Universidade Estadual Paulista; 1994.

[25] Veronezzi F. As reivindicações dos trabalhadores rurais assalariados da lavoura canavieira: a greve de Guariba de 1984 e a luta por terra no interior do estado de São Paulo. Geo UERJ [Internet]. 2015 [acesso em 2016 fev 29];26. Disponível em: http://www.e-publicacoes.uerj.br

[26] Carvalho JG. Questão agrária e assentamentos rurais no estado de São Paulo: o caso da região administrativa de Ribeirão Preto [nternet]. Campinas: Universidade Estadual de Campinas; 2011 [acesso em 2019 mar 13]. Disponível em: http://repositorio.unicamp.br/handle/REPOSIP/286050?mode= full

[27] Word Health Organization - Joint FAO/WHO Consultation. Dietary Exposure Assessment of Chemicals in Food [Internet]. 2005 [acesso em 2016 mar 01]. Disponível em: http://whqlibdoc.who.int/publications/2008/9789241597470_eng .pdf

[28] Pinheiro ABV, Lacerda EMA, Benzecry EH, Gomes MCS, Costa VM. Tabela para avaliação de consumo alimentar em medidas caseiras. $5^{a}$ ed. São Paulo: Atheneu; 2008.

[29] Fisberg RM, Villar BS. Manual de receitas e medidas caseiras para cálculo de inquéritos alimentares. São Paulo: Signus; 2002.

[30] Pais MCN, Valerio LB. Avaliação do consumo de alimentos in natura da população brasileira por meio da Pesquisa de Orçamentos Familiares - bloco de consumo alimentar pessoal (POF 2008/2009). $2^{a}$ ed. São Paulo: ILSI Brasil International Life Sciences Institute do Brasil; 2015 - Toxicologia e avaliação do risco, v. 1 .

[31] Brasil. Ministério da Saúde (MS). Agência Nacional de Vigilância Sanitária (ANVISA). Gerência Geral de Toxicologia. Monografias de agrotóxicos [Internet]. 2016 [acesso em 2016 maio 28]. Disponível em: http://portal.anvisa.gov.br/registros-eautorizacoes/agrotoxicos/produtos/monografia-de-agrotoxicos

[32] Codex Alimentarius. Normas internacionais dos alimentos resíduos de pesticidas nos alimentos [Internet]. 2016 [acesso em 2016 maio 28]. Disponível em: http://www.fao.org/fao-whocodexalimentarius/codex-texts/list-standards/en/

[33] Environmental Protection Agency (EPA). Integrated Risk Information System [Internet]. 2016 [acesso em 2016 maio 28]. Disponível em: https://www.epa.gov/iris

[34] Australian Government. Department of Health. ADI list; 2015.

[35] Meira APG. Ingestão de resíduos de agrotóxicos potencialmente contidos na dieta habitual de escolares [Internet]. Piracicaba: Escola Superior de Agricultura "Luiz de Queiroz" Universidade de São Paulo; 2016 [acesso em 2019 mar 13]. Disponível em: http://www.teses.usp.br/teses 
[36] SAS Institute. The Statistical Analisys System [computer program]. Version 9.3. 2011.

[37] Brasil. Ministério da Agricultura, Pecuária e Abastecimento (MAPA). Instituto Brasileiro do Meio Ambiente e dos Recursos Naturais Renováveis (IBAMA). Agência Nacional de Vigilância Sanitária (ANVISA); Instrução Normativa no 02, de 14 de dezembro de 2015. Autoriza o uso de brometo de metila no Brasil exclusivamente em tratamento fitossanitário com fins quarentenário nas operações de importação e de exportação [Internet]. Diário Oficial da União 21 dez 2015 [acesso em 2019 mar 13]. Disponível em: http://portal.anvisa.gov.br

[38] Jardim ANO. Resíduos de pesticidas em alimentos: validação de metodologia analítica, análise em frutas e avaliação da exposição da população brasileira pelo método probabilístico [Internet]. Brasília: Universidade de Brasília; 2012 [acesso em 2019 mar 13]. Disponível em: http://repositorio.unb.br

[39] Woods HF. Organophosphates. Committee on Toxicity of Chemicals in Food, Consumer Products and the Environment; 1999.

[40] Cantarutti TFP. Risco tóxico de resíduos de pesticidas em alimentos e toxicidade reprodutiva em ratos Wistar [Internet]. Curitiba: Universidade Federal do Paraná; 2005 [acesso em 2019 mar 13]. Disponível em: https://acervodigital.ufpr.br

[41] Mckinlay R, Plant JA, Bell JNB, Voulvoulis N. Endocrine disrupting pesticides: implications for risk assessment. Environ Int [nternet]. 2008 [acesso em 2019 mar 13]; 34(2). Disponível em: https://www.ncbi.nlm.nih.gov/pubmed/17881056

[42] Friedrich K. Desafios para a avaliação toxicológica de agrotóxicos no Brasil: desregulação endócrina e imunotoxicidade. Vigilância Sanitária em Debate [Internet]. 2013 [acesso em 2019 mar 13]; 1(2). Disponível em: https://www.researchgate.net/publication/307757879_Desafios_p ara_a_avaliacao_toxicologica_de_agrotoxicos_no_Brasil_desregula cao_endocrina_e_imunotoxicidade_Challenges_to_toxicological_e valuation_of_pesticides_in_Brazil_endocrine_disruption_and_imm unot

[43] Lee DH, Lee IK, Jin SH, Steffes M, Jacobs DRJ. Association between serum concentrations of persistent organic pollutants and insulin resistance among nondiabetic adults: results from the National Health and Nutrition Examination Survey 1999-2002. Diabetes Care [Internet]. 2007 [acesso em 2019 mar 13]; 30(3). Disponível em: http://care.diabetesjournals.org

[44] Lee DH, Steffes MW, Jacobs DRJ. Can persistent organic pollutants explain the association between serum gamma glutamyl transferase and type 2 diabetes? Diabetologia [Internet]. 2008 [acesso em 2019 mar 13]; 51(3). Disponível em: https://www.ncbi.nlm.nih.gov/pubmed/18071669

[45] Newbold RR. Impact of environmental endocrine disrupting chemicals on the development of obesity. Hormones [Internet]. 2010 [acesso em 2019 mar 13]; 9(3). Disponível em: https://pdfs.semanticscholar.org/94df/654603b49046e764d46e44 5065db1f192bc8.pdf

[46] Jacobsen PR, Axelstad M, Boberg J, Isling LK, Christiansen S, Mandrup KR, Berthelsen LO, Vinggaard AM, Hass U. Persistent developmental toxicity in rat offspring afterlow dose exposure to a mixture of endocrine disrupting pesticides. Reprod Toxicol [nternet]. 2012 [acesso em 2019 mar 13]; 34(2). Disponível em: https://www.sciencedirect.com/science/article/pii/S08906238120 02250?via\%3Dihub

[47] Pesticide Action Network (PAN-UK). A catalogue of lists of pesticides identifying those associated with particularly harmful health or environmental impacts. Briefing Paper List of Lists. Reino Unido: 2001.

[48] Ratnasoorya WD, Ratnayake SSK, Jayatunga YNA. Effects of pyrethroid insecticide ICON (lambda cyhalothrin) on reproductive competence of male rats. Asian J Androl [Internet]. 2002 [acesso em 2019 mar 13]; 4.4 Disponível em: https://pdfs.semanticscholar.org/610a/14e52a95cf7e3b59cb06633 82f56c3a95f5f.pdf

[49] Göettlich P. What are Endocrine Disruptors? 2003.

[50] Pires MV. Desenvolvimento e emprego de um banco de dados para a condução de estudos de avaliação do risco da exposição crônica a resíduos de agrotóxicos na dieta [Internet]. Londrina: Universidade Estadual de Londrina; 2013 [acesso em 2019 mar 13]. Disponível em: http://bdtd.ibict.br

[51] Carneiro FF, Augusto LGS, Rigotto RM, Friedrich K, Búrigo AC. Dossiê ABRASCO: um alerta sobre os impactos dos agrotóxicos na saúde [Internet]. Rio de Janeiro: ABRASCO; 2015 [acesso em 2016 jan 04]. Disponível em: https://www.abrasco.org.br

[52] Brasil. Ministério da Saúde (MS). Agência Nacional de Vigilância Sanitária (ANVISA). Gerência Geral de Toxicologia. Reavaliações de ingredientes ativos de agrotóxicos finalizadas pela ANVISA desde 2006 [Internet]. 2017 [acesso em 2017 junho 22]. Disponível em: http://portal.anvisa.gov.br/registros-eautorizacoes/agrotoxicos/produtos/reavaliacao-de-agrotoxicos

[53] Brasil. Ministério da Saúde (MS). Agência Nacional de Vigilância Sanitária. Resolução - RDC no 45, de 02 de outubro de 2013. Regulamento técnico para o ingrediente ativo acefato em decorrência de sua reavaliação toxicológica [Internet]. Diário Oficial da União 02 out 2013 [acesso em 2019 mar 13]. Disponível em: http://bvsms.saude.gov.br/bvs/saudelegis/anvisa/2013/rdc0045_ 02_10_2013_rep.html

[54] United States Department of Agriculture - USDA. Pesticide Data Program - PDP [Internet]. 2016 [acesso em 2019 mar 13]. Disponível em: https://www.ams.usda.gov/press-release/usdareleases-2016-annual-pesticide-data-program-summary 